\title{
Disordered vergence control in dyslexic children
}

\author{
J F STEIN,' P M RIDDELL', AND S FOWLER \\ From the 'University Laboratory of Physiology, Oxford, and ${ }^{2}$ Royal Berkshire Hospital, Reading
}

SUMMARY By means of a synoptophore vergence eye movements were recorded in dyslexic and normal children while they were attempting to track small targets moving in simulated depth. Of the dyslexic children $64 \%$ were unable to make proper vergence movements when macular sized fusion targets $\left(2^{1 / 2^{\circ}}\right)$ were employed, but their vergence control was better for larger $\left(7^{\circ}\right)$ targets. The normal readers and the remaining dyslexics showed normal vergence responses for both large and small moving fusion stimuli. The results suggest that many dyslexics suffer a disorder of visuomotor control and perception for stimuli falling on the macula; this may explain their characteristic visual problems when reading. Hence recording vergence eye movement responses to small moving fusion stimuli may be useful in the investigation and treatment of children with reading difficulties.

Some $5-10 \%$ of children experience severe problems with learning to read and spell which cannot be attributed to their age, general level of intelligence, or any medical condition.' Specific reading difficulty of this sort is often termed developmental dyslexia. It has often been suggested that a disorder of vision may be at least partly responsible for the condition. But most dyslexics have normal visual acuity and clinically normal eye movements. Moreover most children with poor vision learn to read perfectly well. ${ }^{2}$

Nevertheless many dyslexics find difficulty with stably locating letters or words. They easily lose their place on the page; letters and words seem to blurr, move around, and jump over each other, so that they misidentify and missequence them. These symptoms do not suggest that disorders of the retina or visual pathway, nor grossly abnormal eye movements, are responsible for their problems. Rather they point to the possibility that some dyslexic children may have an imperfect sense of visual direction. In order to locate an object stably in space, retinal signals denoting what it is must be accurately associated with ocular motor signals which indicate the direction in which the eyes are pointing at the time. Then a representation of the real position of the object is maintained in memory; thereafter in normal subjects this location remains stable despite eye movements.

We have put forward the hypothesis that some dyslexic children may be unable to make reliable

Correspondence to Dr J F Stein, University Laboratory of Physiology, Parks Road, Oxford OX1 3PT. retinal/ocular motor associations under certain conditions. ${ }^{3-5}$ We have suggested that they may make their characteristic mislocating and missequencing errors because they cannot converge accurately upon small targets. Thus each eye may point in a slightly different direction and the perceived direction of targets may alter from time to time, depending on which eye's ocular motor signals are used to define them. But our evidence for this hypothesis was indirect, based on children's subjective responses in a complicated vergence task, the Dunlop test ${ }^{6}$ which has turned out to be somewhat unreliable in inexperienced hands. ${ }^{7}$

Here we present direct evidence obtained from recording children's vergence eye movements that two-thirds of a group of 39 dyslexics were unable to converge and diverge accurately in response to simulated movements in depth of small $\left(2^{1 / 2^{\circ}}\right)$ targets. A short account of some of these results has already been published. ${ }^{8}$

\section{Material and methods}

Over a 3-month period 44 children aged 8 to 11 years were referred by local general practitioners and school medical officers to the orthoptic department of the Royal Berkshire Hospital, Reading, because their reading was thought to be backward. Thirtynine of these children were found to have a reading age more than 2 standard deviations behind that expected from their performance intelligence 
quotient (IQ) using the British Ability Scales (BAS). ${ }^{9}$ They were therefore classified as dyslexic. They had no ophthalmological or other medical conditions which might have explained this discrepancy. Twenty-four children of similar age and performance IQ but whose reading was at or above that expected from their IQs were also studied as normal controls.

All the children were given thorough ophthalmological and orthoptic examinations. The movements of each eye were recorded during synoptophore vergence tests by measuring changes in the amount of infrared light reflected from it. ${ }^{10}$ Our equipment enabled us to record the position of each eye over a $20^{\circ}$ linear range with a resolution of $10^{\prime}$ arc. The children were asked to inspect two fusion slides, either the Dunlop test houses which subtended $2 \frac{1}{2^{\circ}}$ or large $\left(7^{\circ}\right)$ fusion targets. With the synoptophore tubes parallel they were requested to fuse the pictures; then, while the synoptophore tubes were abducted or adducted at approx. $1 / 2 \%$ they were asked to maintain fusion for as long as they could. Their eye movements were measured during this procedure. They were asked to report their perceptual experiences and to indicate when diplopia intervened by pressing a key.

\section{Results}

Fig. 1A shows the vergence responses of one of the 24 normal children during the synoptophore tests. His two eyes moved symmetrically towards or away from each other from the start of the test (s in the figure). Thus each eye tracked its own target independently, and diplopia intervened (2) after about $20^{\circ}$ convergence or $5^{\circ}$ divergence from parallel. All 24 of the normal readers together with $14(36 \%)$ of the dys-

\section{$2 \frac{1}{2} 0$ fusion targets}

Divergence Convergence

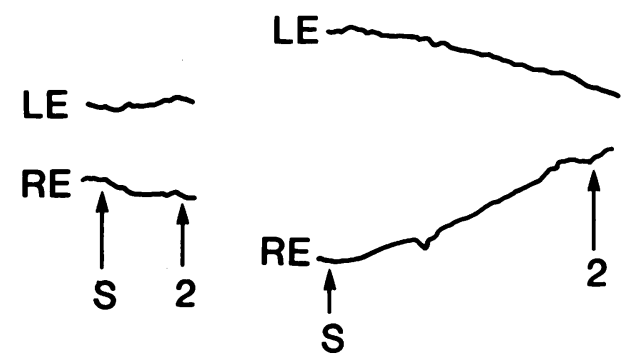

\section{$7^{\circ}$ fusion targets}

\section{Convergence}

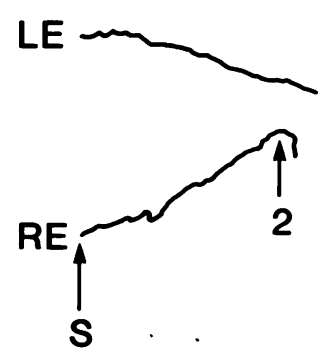

\section{$2^{\frac{1}{2}}$ fusion targets}

Divergence Convergence

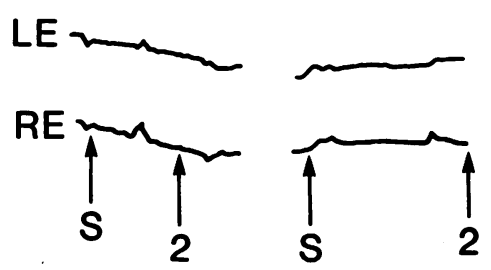

$7^{\circ}$ fusion targets

Convergence

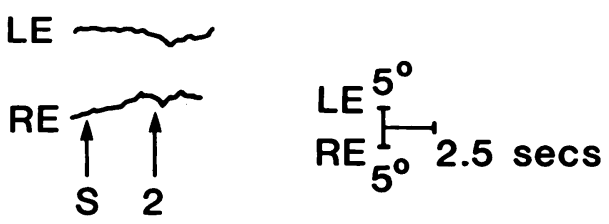

Fig. 1 A: Normal rèader. Vergence eye movements tracking macular $\left(2^{1} 1^{\circ}\right)$ and large $\left(7^{\circ}\right)$ fusion targets. B: Dyslexic subject. Attempts at vergence. Note inappropriate conjugate eye movements. 
lexics showed this kind of normal vergence response in the test.

In contrast Fig. 1B shows records taken from one of the remaining 25 dyslexics. It can be seen that, when this child attempted to track the macular sized targets, instead of diverging or converging properly his two eyes tended to move in parallel, following just one of the targets, because he made inappropriate conjugate (version) movements. The two eyes seemed not to be able to move independently in opposite directions. Because both eyes followed each other in parallel, the target seen by one eye moved quickly off the fovea, leading either to diplopia or to suppression of that image. So the child reported either diplopia after only $1^{\circ}$ attempted divergence or convergence, or that one of the targets seemed to disappear. When this dyslexic was asked to track the large $\left(7^{\circ}\right)$ fusion targets in the synoptophore, however, these difficulties were far less obvious. Twentyfive of the dyslexic children $(64 \%)$ showed these abnormal vergence responses to small but not to large targets. Thus the vergence control of these subjects was clearly different from that of the normal readers and the other 14 dyslexics.

In our previous studies ${ }^{3-5}$ we used the Dunlop synoptophore test ${ }^{6}$ to obtain an indirect indication of the accuracy of dyslexics' vergence control. This is a subjective test in which a child views macular sized fusion stimuli in the synoptophore. He/she is asked to report what movements 'control' targets presented to each eye separately appear to make during divergence of the tubes. Normal readers and about onethird of dyslexic children can maintain fusion for up to $5^{\circ}$ of divergence. They report that the control target seen by one eye-the 'reference eye'appears to remain stationary. On repeated testing it is always the target on the other side which appears to move. These children are said to have stable responses in the Dunlop test.

However, two-thirds of dyslexics give unstable and inconsistent responses. ${ }^{3-5}$ They experience diplopia after less than $2^{\circ}$ divergence of the synoptophore tubes. The targets seem to disappear, move around jerkily, and on repeated testing both targets or first one and then the other appear to move. In our present sample of children the 24 normal readers, and the 14 dyslexics with good vergence responses to the small fusion targets, as indicated by our eye movement recordings, had stable Dunlop test responses, whereas all 25 dyslexics who showed poor vergence control in the eye movement recordings gave unstable Dunlop test reports.

In order to confirm our qualitative impression of the difference between the vergence of dyslexics who reported stable impressions in the Dunlop test compared with those who had unstable experiences we estimated the average size of the vergence eye movements which our subjects were able to make before fusion broke in the four synoptophore tests (abduction or adduction using $2 \frac{1 / 2^{\circ}}{}$ or $7^{\circ}$ fusion stimuli). We measured the maximum difference between the positions of the eyes during three trials under each condition and averaged the three together. We compared this figure with the magnitude of any conjugate movements made during the trials. Fig. 2 shows the divergence results for normal children, dyslexics with stable Dunlop test responses, and dyslexics with unstable Dunlop responses. It will be seen that the normal readers were able to make good sized covergent movements when tracking the macular fusion targets in the synoptophore (mean $6 \cdot 5^{\circ}, \mathrm{SE} 1 \cdot 3^{\circ}$, Fig. 2B). Similarly their divergence was satisfactory (Fig. 2A) (mean $2.4^{\circ}$, SE $0.3^{\circ}$ ) for the $2 \frac{1}{2}{ }^{\circ}$ targets. They made few inappropriate conjugate movements; these averaged only $0 \cdot 8^{\circ}$, SE $0.2^{\circ}$, in amplitude.

However, the 24 dyslexic children with unstable Dunlop test responses were able to make only very small vergence movements. They could converge on average by only $3 \cdot 3^{\circ}$, SE $1.8^{\circ}$, and diverge by only $0 \cdot 3^{\circ}$, SE $0 \cdot 3^{\circ}$, when attempting to track the macular sized stimuli. Instead they tended to make inappropriate conjugate movements. These averaged $1.4^{\circ}$, SE $0.3^{\circ}$, in divergence and $1.9^{\circ}, \mathrm{SE} 0.4^{\circ}$, in convergence trials, and of course they led to early diplopia. Like the normal subjects however, the 14 dyslexic children with stable responses in the Dunlop test were able to track the macular fusion targets satisfactorily in both convergence and divergence.

When the children were asked to track the large $\left(7^{\circ}\right)$ fusion targets in the synoptophore the differences between the groups were much less pro-

Amplitude of divergent eye movements
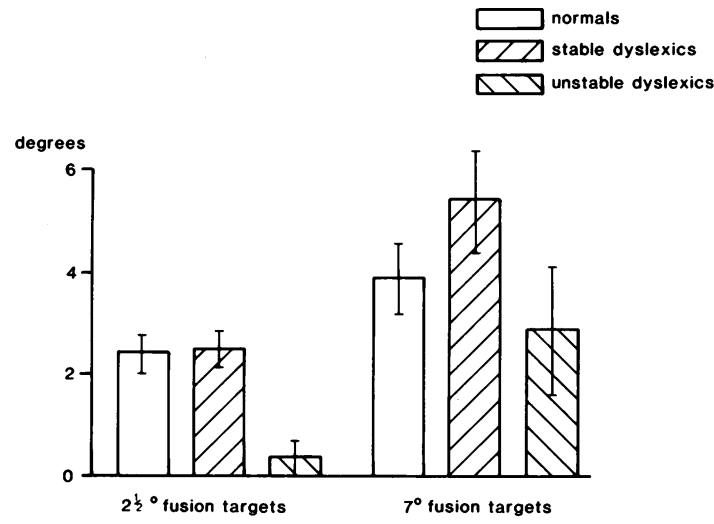

Fig. 2A Amplitude of divergent eye movements in normal readers, dyslexics with stable Dunlop test responses, and dyslexics with unstable responses in the Dunlop test. 
nounced. In divergence there were no significant differences, though in convergence the unstable dyslexics were still somewhat worse than those with stable Dunlop test responses. Overall the children's eye movement responses to the macular sized $\left(2 \frac{1}{2}{ }^{\circ}\right)$ targets provided much better discrimination between those with good and bad vergence control than using the larger $\left(7^{\circ}\right)$ stimuli.

\section{Discussion}

The question whether the abnormal eye movements which may be demonstrated in dyslexic children with reading difficulties are a cause or a consequence of their problems has been vigorously debated over the past few years." The consensus now appears to be that, while dyslexics may show mild esophoria and minor disturbances of smooth pursuit, ${ }^{12}$ their saccadic control is probably fundamentally normal. ${ }^{13}$ The excessive number of regressions, etc., which may be observed when dyslexics attempt to read may well be simply the result of their not understanding what they are seeing. However, dyslexics' vergence eye movements seem never to have been investigated in detail even during reading. The present report is the first in which eye movement recordings have been used to demonstrate differences between the vergence movements of dyslexics and those of normal children. It did not require written material or stimuli with any linguistic content at all to reveal these differences.

Amplitude of convergent eye movements

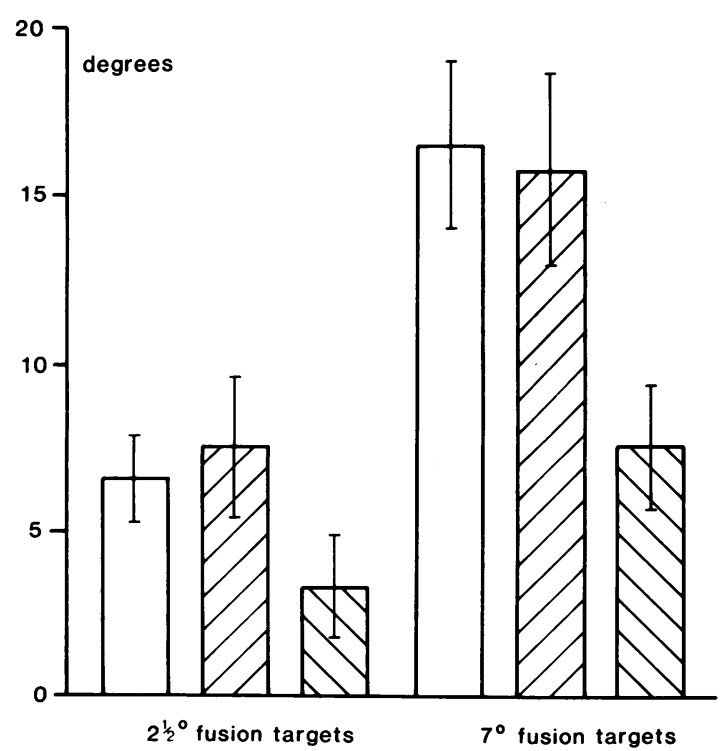

Fig. 2B Amplitude of convergent eye movements.
Although our study was not blind, in that the investigators knew which children were dyslexic and which were normal readers, clearly this knowledge could not have influenced the eye movement recorder. Two-thirds of the dyslexic children were found to have vergence control which was qualitatively different from normal; but a third of the dyslexics had normal responses. These proportions are similar to those we had previously found using the much more subjective Dunlop test. ${ }^{3-51+}$

Our results suggest an explanation of why dyslexics' vergence movements have not been implicated before. We found that their vergence was poor only when they were asked to track small fusional stimuli moving in apparent depth. With larger stimuli such as the $7^{\circ}$ targets which we also tested, or the large sliding stage of the RAF rule used by many orthoptists, dyslexics' fusional control is usually found to be within normal limits. ${ }^{12}$

There are particular difficulties associated with guiding vergence eye movements in response to small fusion targets moving in depth. For fine vergence control it is necessary for the macular signals generated by each eye to be distinguishable, so that each set can be routed back to guide the movements of the eye that provided them on to its target, independently of what the other eye is doing. This is known as utrocular control. But for macular vision there is no natural neuroanatomical substrate by which utrocular control can easily be achieved. Both ipsilateral and contralateral halves of the central visual field are represented in each hemisphere. The contralateral half is projected via the classical retinogeniculate pathway. But the ipsilateral half of the central visual field reaches each hemisphere via fibres from the temporal side of the macula which cross aberrantly in the optic chiasm, ${ }^{15}$ and via the opposite hemisphere and the splenium of the corpus callosum. Within the visual cortex signals coming from each eye are usually segregated into clearly demarcated strips of columns dealing with each eye, so that the position of each column represents not only the retinotopic location of the stimulus but also the eye which provided the signal. But in the region of areas 17 and 18 representing the macula this neat organisation breaks down. ${ }^{16}$

Visually guided eye movements are probably controlled mainly by the right hemisphere. ${ }^{17}$ Somehow the information required for guiding each eye independently for vergence control must be selected from the mixture of right and left eye signals forming the representation of the macula in the right hemisphere. We have shown that by the age of 5 years only $50 \%$ of normal children have achieved utrocular control which is sufficiently reliable to enable accurate vergence movements to be made in response to small 
fusional stimuli. ${ }^{78}$ As each year passes around $8 \%$ more children develop good fine vergence control. But we find that many dyslexic children fail to develop this control successfully, until much later, if at all. This delay may explain their poor reading.

One-third of dyslexics have normal vergence control however. We have recently shown ${ }^{19}$ that these children are more likely to make the phonemic segmentation errors described by Bradley and Bryant $^{20}$ than the visual localisation errors which we find to be characteristic of dyslexics with visuomotor problems.

Dyslexics' specific reading difficulties are probably at root a consequence of disordered hemispheric specialisation. ${ }^{21}$ But we do not yet know enough about the different processing styles of the two hemispheres to understand the mechanisms by which their malfunctioning may lead to reading difficulties. Our-results throw a little light on this problem, however. Learning to read demands at the outset both accurate visuomotor control in order to localise and sequence letters properly (perhaps this is primarily a right hemisphere function), together with the ability to categorise phonemes correctly in order to relate the order of the sounds in a word to their written representations (probably a task for the left hemisphere). It is reasonable to speculate therefore that two ways in which disordered hemispheric specialisation may lead to reading problems are: (1) by disturbing the development of precise visuomotor control; and (2) by preventing the acquisition of accurate phonemic segmentation. The motor theory of language comprehension suggests that the latter may be a left hemisphere analogue of the visuomotor disorder, since it is probably an audiomotor accomplishment. ${ }^{22}$ The spatial, temporal, and logical sequencing problems and the characteristic linguistic difficulties which dyslexics suffer $^{23}$ may then be secondary consequences of failure of these basic perceptumotor processes to develop properly.

It might be argued that the chain of events is the other way about. Perhaps in normal children learning to read is the influence which brings about stable vergence control and successful phonemic segmentation. Although the requirements of reading may stimulate and assist the development of accurate vergence and phonemic segmentation, it seems inherently implausible that such fundamental perceptuomotor processes should be entirely secondary to reading progress. We have shown that the acquisition of stable visuomotor control precedes improvements in reading; ${ }^{19}$ and Bradley and Bryant have analogous results for phonemic processing. ${ }^{21}$ Furthermore procedures designed to improve vergence control, such as monocular occlusion, ${ }^{19}$ as well as those aimed at assisting phonemic segmenta- tion, such as training in sound classification, ${ }^{20}$ are often followed by improvements in reading. These findings suggest that a child needs to develop these basic visuomotor and phonological abilities before he can begin to learn to read properly.

We thank Mr J McMillan, who was these children's ophthalmologist; the Oxford Regional Health Authority Locally Organised Research Scheme together with the Camilla Samuel Fund for financial assistance; and $\mathrm{Mr} \mathrm{J}$ Haines and $\mathrm{MrC}$ Annetts for help with the design of the eye movement recorder.

\section{References}

1 Rutter M, Yule WJ. The concept of specific reading retardation. Child Psychol Psychiatry 1975; 16: 181-97.

2 Vellutino FR. Psychological factors in specific reading disability. In: Benton AL, ed. Dyslexia. New York: Oxford University Press, 1978.

3 Stein JF, Fowler MS. Visual dyslexia. Br Orthopt J 1980; 7: 11-4.

4 Stein JF, Fowler MS. Visual dyslexia. Trends Neurosci 1982; 4: $77-80$.

5 Stein JF, Fowler MS. A physiological theory of visual dyslexia. In: Rose FC, ed. Advances in neurology. New York: Raven Press, 1984: 42

6 Dunlop P. Dyslexia, the orthoptic approach. Aust Orthopt J 1972; 12: 16-20.

7 Stein JF, Riddell PM, Fowler MS. The Dunlop test and reading in primary school children. $\mathrm{Br} J$ Ophthalmol 1986; 70: 17-20.

8 Fowler MS, Riddell PM, Stein JF. Vergence eye movements in normal and dyslexic children. J Physiol (Lond) 1985; 369: 41P.

9 Thompson ME. The assessment of children with specific reading difficulties using the British Ability Scales. BrJ Psychol 1982; 73: 461-78.

10 Robinson DA. Control of eye movements. Handbook of physiology. Baltimore: Williams and Wilkins, 1981; 2 (2): 1275-320.

11 Pavlidis ST. Do eye movements hold the key to dyslexia? Neuropsychologia 1981; 19: 57-64.

12 Helveston EM, Billips WC, Weber JC. Controlling eye, dominant hemisphere relationships in reading disability. Am J Ophthalmol 1976; 70: 96-100.

13 Stanley S, Smith SA, Howell EA. Eye movements and sequential tracking in dyslexic children. Br J Psychol 1983; 74: 181-7.

14 Stein JF, Fowler MS. Diagnosis of dyslexia by means of a new indicator of eye dominance. BrJ Ophthalmol 1982; 66: 332-6.

15 Stone J, Leicester J, Sherman SM. The nasotemporal division of the monkey's retina. J Comp Neurol 1973; 150: 333-56.

16 Levay S, Connolly M, Houde J, Van Essen DC. The complete pattern of ocular dominance stripes in the striate cortex and visual field of the macaque monkey. J Neurosci 1985; 5: 486-501.

17 DeRenzi E, Colombo A, Faglioni P. Gilbertoni M. Conjugate gaze paresis in stroke patients with unilateral damage. Arch Neurol 1982; 39: 482-6.

18 Stein JF, Fowler MS. 'Ocular motor' dyslexia. Dyslexia Review 1982; 5: $25-8$.

19 Stein JF, Fowler MS. Effect of monocular occlusion on visuomotor perception and reading in dyslexic children. Lancet 1985 ii: $69-73$.

20 Bradley L, Bryant PE. Categorising sounds and learning to read A causal connection. Nature 1983; 301: 419 .

21 Galaburda AM, Geschwind N. Cerebral dominance Cambridge, Mass: Harvard University Press, 1984.

22 Liberman AM, Cooper FS, Shankweiler DP, Studdert Kennedy M. A motor theory of speech perception. Psychol Rev 1967; 74: 431 .

23 Coltheart M, Masterson J, Byng S, Riddock J, Prior M. Surface dyslexia. QJ Exp Psychol 1983; 35A: 469-96.

Accepted for publication 27 January 1987. 